\title{
Structural Equation Modeling to Analyze Person-Organization Fit and Organizational Effectiveness
}

\author{
Hadi Teimouri ${ }^{1}$, Kouroush Jenab ${ }^{2}$, Somaye Rafei ${ }^{3}$, Maryam Yonespoor ${ }^{4}$ \\ ${ }^{1,3,4}$ Management Department, University of Isfahan, Isfahan, Iran \\ ${ }^{2}$ Faculty of Department of Engineering Sciences, College of Aeronautics, Embry-Riddle Aeronautical University, USA
}

\begin{tabular}{l}
\hline \hline Article Info \\
\hline Article history: \\
Received Jun 22, 2016 \\
Revised Sep 20, 2016 \\
Accepted Oct 4, 2016 \\
\hline
\end{tabular}

\section{Keyword:}

Organizational effectiveness Person-individual fit Structural modeling

\begin{abstract}
Efficient management and leadership can be achieved via precise planning for selection, recruitment, and optimization of the labor force. One of the major goals in labor force selection and recruitment is the fit between people and an organization. This phenomenon is known as person-individual fit. In this research, the authors collected data via a survey aimed at exploring the relationship between person-individual fit and organizational effectiveness at the University of Isfahan. The research hypotheses were tested through variables such as environmental congruence, KSA (Knowledge, Skills, Abilities) congruence, goals congruence, values congruence, and personality congruence, as dimensions of person-individual fit. The aim of this study is developing and practical and from the procedure implemented is introducinganalyzing. The sample studied in this study is the mangers and employers of the university in Isfahan. A stratified random sampling method was used based the Morgan table and a sample size of 120 was chosen from among 150 persons. The results revealed that there is a significant relationship between dimensions of person-individual fit and organizational effectiveness.
\end{abstract}

Copyright $@ 2016$ Institute of Advanced Engineering and Science. All rights reserved.

\section{Corresponding Author:}

Kouroush Jenab,

Faculty of Department of Engineering Sciences,

College of Aeronautics,

Embry-Riddle Aeronautical University,

600 S. Clyde Morris Blvd. Daytona Beach, FL 32114-3900, USA.

Email: kouroush.jenab@erau.edu

\section{INTRODUCTION}

During the time, organizations found out that one of the major concerns in both the private and public sectors is to increase employees' productivity and promote their efficiency, since demand for offering high quality and better services is increasing [1]. Person organization fit is related to conformity with individual and organizational characteristics and is created when at least one of them satisfies another's needs or have common major characteristics; or even both states exist [2-3]. Person organization fit is one element of the wider concept of person environment fit which historically roots in Levin's thinking (1935). It means that the individual's behavior subjects to the individual and his.her environment. Satisfaction, productivity, creativity and stability are enhanced whenever there is such fit [4]. Recent studies on business strategy have shown that competitive advantage for organizations can be obtained via human resource concentration as the most important strategic source for the organization. In other words, human resources are a kind of intangible asset, which can result in the establishment of values for the organization in order to be able to face the current turbulent environment [5]. This feature emphasizes the fact that human resource strategies must be interwoven into the texture of the organization and support realization of its purposes [6].

There are many researches of person-individual fit at the important issue in the organization. Recently study in this can be referred is exploring the relationship between person-Organization Fit and 
organizational citizenship behavior. In this study, the authors collected data via a survey aimed at exploring the relationship between person-individual fit and organizational citizenship behavior at the University of Isfahan. The research hypotheses were tested through variables such as workplace congruence, KSA (knowledge, skills, abilities) congruence, goals congruence, values congruence, and personality congruence, as dimensions of person-individual fit [7].

In this paper, the authors collected data via a survey aimed at exploring the relationship between person-individual fit and organizational effectiveness at the University of Isfahan. Assuming that managers and staff can be a fundamental issue for the organization's human capital and to develop appropriate (inappropriate) students are considered, it seems the factors influencing their attitudes and behaviors can be many key issues, invest in human resources in organizations to achieve competitive advantage. Therefore, this study aimed to evaluate the fit between features and characteristics of university staff and managers to determine the consequences of their attitude and relationship with OE's important.

Academic environments such as universities, certain behavioral expectations is felt. Directors and staff of the university who have been chosen to have university degrees and in administrative and responsibility seem formidable. So we decided to measure perceptions of the relationship between personorganization fit and organizational effectiveness in the reality of the organization.

\section{RESEARCH METHOD}

\subsection{Effectiveness}

Hoy and Mishkle believe that each organization has to employ the best resources; deals successfully with external threatening forces; leads their energy towards the main objective of the organization; and develops it permanently by maintaining its ability and sustainability besides compatibility with the changeable environment and confronting with any problem in order to be effective [8]. Previous studies on effectiveness disclose that there is not the best way for effectiveness, because it depends on the viewpoint of management in any organization with regard to effectiveness. In fact, the topic, purpose and ways of achieving effectiveness should be clear in organizations for employees and then management should try to internalize the characteristics about effectiveness as a common viewpoint for all organizational members [9]. Robins (1990) defines organizational effectiveness as degree of achieving short term and long term goals considering the expectations of beneficiaries, assessment, and organizational life level [10].

\subsection{Effectiveness from Parsons' Viewpoint}

Effectiveness has been considered in each model from different angles. Talcott Parsons (1970) explained effectiveness in a relatively perfect model and proposed a model to evaluate organizational effectiveness. There are four components including adaptation, goal attainment, integration, and pattern maintenance.

a. Adaptation: One of the main activities of organizations is adaptation that is also an important sign for organizational effectiveness. Adaptation emphasizes compatibility of an organization with its environment as well as compatibility of the environment with organizational needs.

b. Goal attainment: emphasizes determining of purposes and collecting the required resources and energy to achieve objectives of the organization. Among normal signs of goal attainment for manufacturing firms, identification of resources, higher production, etc. can be mentioned.

c. Integration emphasizes: Integration emphasizes the need for unity and relationship among constituent units of a system in an organization.

d. Pattern maintenance: Pattern maintenance emphasizes establishment and maintenance of culture, values, behavior, and ideology [11].

Parsons explicitly indicates that these functions are essential for identification of resources and can be regarded as objectives of the organization. Thus, all systems should solve four functional components, i.e. adaptation, goal attainment, integration, and pattern maintenance.

\subsection{Person-Organization Fit}

Basically, person organization fit theory determines that there are some characteristics in organizations which have the potential of compatibility with individuals' characteristics and also it determines that individuals' behaviors and attitudes are influenced by degree of compatibility or fit among the individuals and organizations [12]. Results of studies have revealed that a higher level of person organization fit can create higher levels of organizational attractiveness. Generally, the topic of person organization fit has been proposed as an effective and important factor to answer to the question that why individuals are attracted to a specific organization, or selected by a specific organization and finally remain in a specific organization. Much interest in investigation in this field can to some extent due to the fact that a lot of 
positive results can be predicted through person organization fit. For compatibility of the organization's requirements including knowledge, skill and capabilities, this approach fits job, executive and technical requirements of individuals for efficient execution of their tasks [13].

Studies show that whatever person organization fit is higher, job consequences will be more positive. Lower levels of stress, job involvement, higher organizational commitment, better job attitudes, higher performance rates, and lower turnover are some of these consequences [14].

When it is talking about person organization fit, personality compatibility, attitudes and values of the individual are compared with values, purposes, structures, procedures and culture of the organization [2]. Different methods have been mentioned to measure person organization fit. Christoph (1996) divided these methods into three classes: mental fit, perceived fit, and objective fit.

a. Mental fit: This standard asks individuals directly how much their characteristics fit with those of the organization in which they work. There is no clear standard in this method to measure characteristics of individuals and organizations; rather respondents justify about the consistency among their own characteristics and their conception of those of the organization.

b. Perceived fit: It is similar to mental fit conceptually but different from it practically. In this method, the difference between the individual's self-concept and his.her conception about the organization is measured. Through a questionnaire, this standard asks the respondent to describe his.her characteristics as well as those of the organization.

c. Objective fit: Both standards of mental fit and perceived fit are in opposition with objective fit. It asks the individual to describe his.her own characteristics and then asks other employees to describe characteristics of the organization. Thus, consistency and agreement among perceptions of organizational members are evaluated [15].

Based on this framework, people look for organizations that are attractive to them; that is, they are attracted as an organizational member and whenever there is no attraction for both parties (the person and the organization) they would leave the organization [16]. Kristof (1996) defined person-individual fit as congruence among the individuals and organizations in which they work. Basically, the person-individual fit theory states that the existing characteristics of organizations have the potential of congruence with the characteristics of the individuals and their behaviors, and that attitudes are affected by the degree of congruence or fit among the individuals and the organization [17].

Previous studies and theoretical principles on the measurement indexes of person-individual fit have proposed five standards by which to measure person-individual fit, based on which relationships among fit and its attitudinal consequences are investigated. These five standards are KSA congruence, personality congruence, workplace congruence, goals congruence, and personality congruence [15]. In these studies, the values standard was used more than other standards to measure the degree of congruence among the values of individuals and organizations (78\%). Forty-one percent of the studies used the personality fit criterion, $20 \%$ used the standard of goals congruence, and only three studies (less than 1\%) used the KSA congruence standard to measure degree of fit. Thirty-five percent of these studies used multiple standards, including workplace congruence, to measure degree of fit; and, $43 \%$ did not propose a special standard nor did they completely measure the degree of fit. Therefore, the values congruence was ranked the highest, while personality congruence and goals congruence were ranked second and third, respectively.

\subsubsection{Values Congruence}

Adherents of person organization fit believe that individuals whose values proportion to those of the organization play a role in effectiveness of the organization and less likely they leave the organization [18]. Value compatibility is essential for person organization fit. Studies show that those who have similar values to their organization are attracted faster and their willingness to remain in that organization will be higher [19].

\subsubsection{Workplace Congruence}

Degree of fit between the individual and the environment in which he.she works is a concept that its record returns to previous years and in discussions on human resource management and psychology. When individuals' personality is conformed to characteristics of the environment, they are happier and more successful in their workplace [20].

\subsubsection{KSAs Congruence}

This approach deals with proportionality of individuals' job, executive, and technical requirements to do their tasks efficiently [21]. Exploring this fit can show effectiveness of individuals as well as relations among fit and the related consequences [22]. The literature related to employee selection concentrates mainly on congruence between an individual's KSA and organizational requirements [23]. This approach deals with 
the fit of an individual's job and executive and technical requirements, as they relate to completing tasks effectively [16]. Exploring this fit can show a person's effectiveness as well as the relationship between fit and related consequences [24].

\subsubsection{Personality Congruence}

Many studies have shown that there are positive relationships between the limit to which a person is attracted to an individual or group and the limit to which the person describes that individual or group to be similar to him.herself [25]. Tom (1971) found that people prefer organizations having the highest similarity to their personality characteristics [26].

Recent discussions on the principles of person-individual fit show a kind of structural improvement and reinforcement of personality fit via the personality model of the organization [25]. This approach indicates that attitudinal models and beliefs in a certain situation can be obtained based on an "ideal" successful character or a reference inside the organization. As such, conformity between individuals' personalities and the ideal personality of the organization can create a criterion by which to evaluate congruence among the individuals and organizations and, finally, provide another approach to the measure of person-individual fit [25].

\subsubsection{Goals Congruence}

The ASA framework by Schneider et al. (1995) shows the goals congruence as an important dimension of person-individual fit [27]. According to this framework, people are attracted to organizations whose purposes are congruent with their own purposes. Thus, the goals congruence includes the similarity between purposes of the organization and those of its employees [15].

\subsection{Conceptual Model}

Person-organization fit consists of five dimensions: workplace congruence, personality congruence, values congruence, goals congruence, and KSA congruence. As was mentioned earlier, this study explored the relationship between person-organization fit and dimensions of organizational effectiveness. The model of the study is shown in Figure 1.

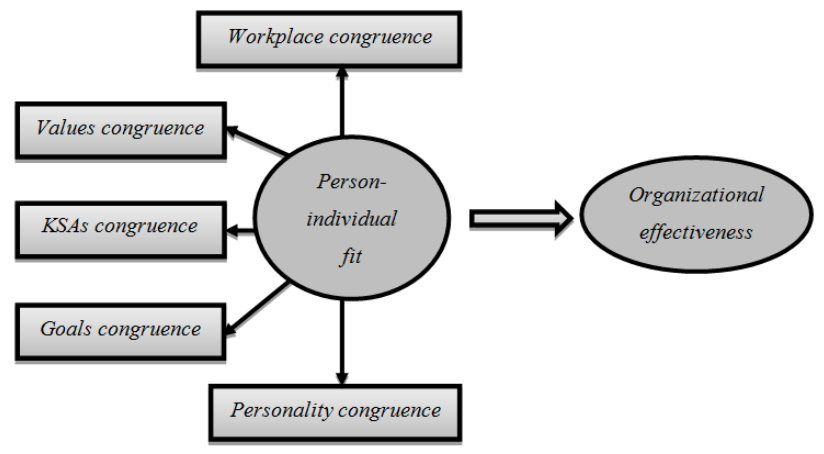

Figure 1. The Research Model

\subsubsection{Research Hypotheses}

Main hypothesis: There is a significant relationship between person-organization fit and organizational effectiveness among the employees at the University of Isfahan.

Secondary hypotheses:

$\mathrm{H}_{1}$ : There is a significant relationship between workplace congruence and organizational effectiveness among the employees at the University of Isfahan.

$\mathrm{H}_{2}$ : There is a significant relationship between KSA congruence and organizational effectiveness among the employees at the University of Isfahan.

$\mathrm{H}_{3}$ : There is a significant relationship between goals congruence and organizational effectiveness among the employees at the University of Isfahan.

$\mathrm{H}_{4}$ : There is a significant relationship between personality congruence and organizational effectiveness among the employees at the University of Isfahan.

$\mathrm{H}_{5}$ : There is a significant relationship between values congruence and organizational effectiveness among the employees at the University of Isfahan. 


\subsubsection{Methodology}

This was a practical study from an objective standpoint and descriptive from a methodological perspective. Library studies including books and academic journals was used to collect data on the research literature and standard questionnaires were used to test the hypotheses. A standard questionnaire (39 questions) by Parsons' viewpoint was used in this study. A standard questionnaire including 39 questions was used to measure the variables. In this questionnaire, including 39 questions was employed to measure the variables that includes 20 questions about dimensions of person organization fit (questions 1-2-6-11 were about workplace compatibility; questions 3-9-14-13 were about KSAs compatibility; questions 4-12-19-20 were about goal compatibility; questions 5-8-10 were about personality compatibility; and questions 7-15-1617 were about value dimension), 19 questions about organizational effectiveness were adopted from Parsons' scale (questions 21-26 were about adaptation; questions 27-30 were about goal attainment; questions 31-35 were about integration; and questions 36-39 were about pattern maintenance).

Also, this study was cross-sectional in terms of time. A stratified random sample was taken from the population of experts and managers at the University of Isfahan. The sample size was 120 .

\section{RESULTS AND ANALYSIS}

Content validity was used to confirm validity of the questionnaire (using the opinions of professors and experts in the field of marketing and consumer behavior) as shown in Table 1.

Table 1. Results of the Cronbach's Alpha

\begin{tabular}{lc}
\hline \multicolumn{1}{c}{ variables } & Cronbach's alpha \\
\hline person-organization fit & 0.84 \\
organizational effectiveness & 0.92 \\
\hline
\end{tabular}

\subsection{Normality of the Statistical Population Distribution}

The Kolmogorov-Smirnov test was employed to test the normality of the data distribution. The results are shown in Table 2.

Table 2. Results of the Normality Test

\begin{tabular}{lccc}
\hline \multicolumn{1}{c}{ Variable } & mean & $\begin{array}{c}\text { standard } \\
\text { deviation }\end{array}$ & $\begin{array}{c}\text { significance } \\
\text { level }\end{array}$ \\
\hline Person-individual fit & 2.82 & 0.83 & 0.059 \\
organizational effectiveness & 2.59 & 0.66 & 0.054 \\
\hline
\end{tabular}

According to the results in Table 2, and given that the significance level of the test was above 0.05 , the claim that the questions were normal was accepted and parametric tests as well as the ML method (maximum likelihood for multivariate normal distributions) could be used in structural equation modeling.

\subsubsection{Exploring the Mean Value Test of the Research Variables}

A one-sample t-test was used to analyze the status of the variables. Maximum and minimum scores for each dimension in the questionnaire, based on a Likert-type scale, were equal to five and one, respectively. A score higher than three showed desirability of the given variable. The results of the mean test of the research variables are given in Table 3 .

A one-sample t-test showed that all of the variables received average-average scores except sportsmanship, given the significance level and mean. 
Table 3. Mean of Factors and t-test

\begin{tabular}{lccc}
\hline \multicolumn{1}{c}{ Variable } & mean & t-test & significance level \\
\hline Adaptation & 2.55 & -6.88 & 0.000 \\
Goal attainment & 2.35 & -9.69 & 0.000 \\
Integration & 2.67 & -4.43 & 0.000 \\
Pattern maintenance & 2.82 & -2.26 & 0.025 \\
Workplace congruence & 2.54 & -6.15 & 0.000 \\
KSAs congruence & 1.72 & -28.12 & 0.000 \\
Goals congruence & 2.09 & -17.91 & 0.000 \\
Values congruence & 2.03 & -16.79 & 0.000 \\
Personality congruence & 1.92 & -21.51 & 0.000 \\
organizational effectiveness & 2.59 & -6.55 & 0.000 \\
Person-individual fit & 2.06 & -24.15 & 0.000 \\
\hline
\end{tabular}

\subsubsection{Results of Testing the Hypotheses}

Structural equation modeling was used to test the hypotheses. For this reason, a confirmatory factor analysis was conducted first. The results are shown in Table 4.

Table 4. Results of the Confirmatory Factor Analysis

\begin{tabular}{lccccccc}
\hline \multicolumn{1}{c}{ variables } & CFI & NFI & IFI & TLI & GFI & RMR & CIMIN.DF \\
\hline Workplace congruence & 1.000 & 0.99 & 1.000 & 0.99 & 0.99 & 0.008 & 1.21 \\
KSAs congruence & 0.97 & 0.96 & 0.97 & 0.92 & 0.97 & 0.02 & 2.46 \\
Goals congruence & 1.000 & 1.000 & 1.000 & 1.000 & 1.000 & 0.001 & 1.002 \\
Values congruence & 1.000 & 0.99 & 1.000 & 1.000 & 0.99 & 0.004 & 1.13 \\
Personality congruence & 1.000 & 0.98 & 1.000 & 1.000 & 0.99 & 0.01 & 1.59 \\
Adaptation & 0.96 & 0.92 & 0.96 & 0.93 & 0.95 & 0.04 & 1.89 \\
Goal attainment & 0.99 & 0.98 & 0.99 & 0.95 & 0.99 & 0.01 & 2.52 \\
Integration & 1.000 & 0.99 & 1.000 & 1.000 & 0.99 & 0.013 & 1.29 \\
Pattern maintenance & 0.98 & 0.97 & 0.98 & 0.94 & 0.97 & 0.04 & 2.93 \\
\hline
\end{tabular}

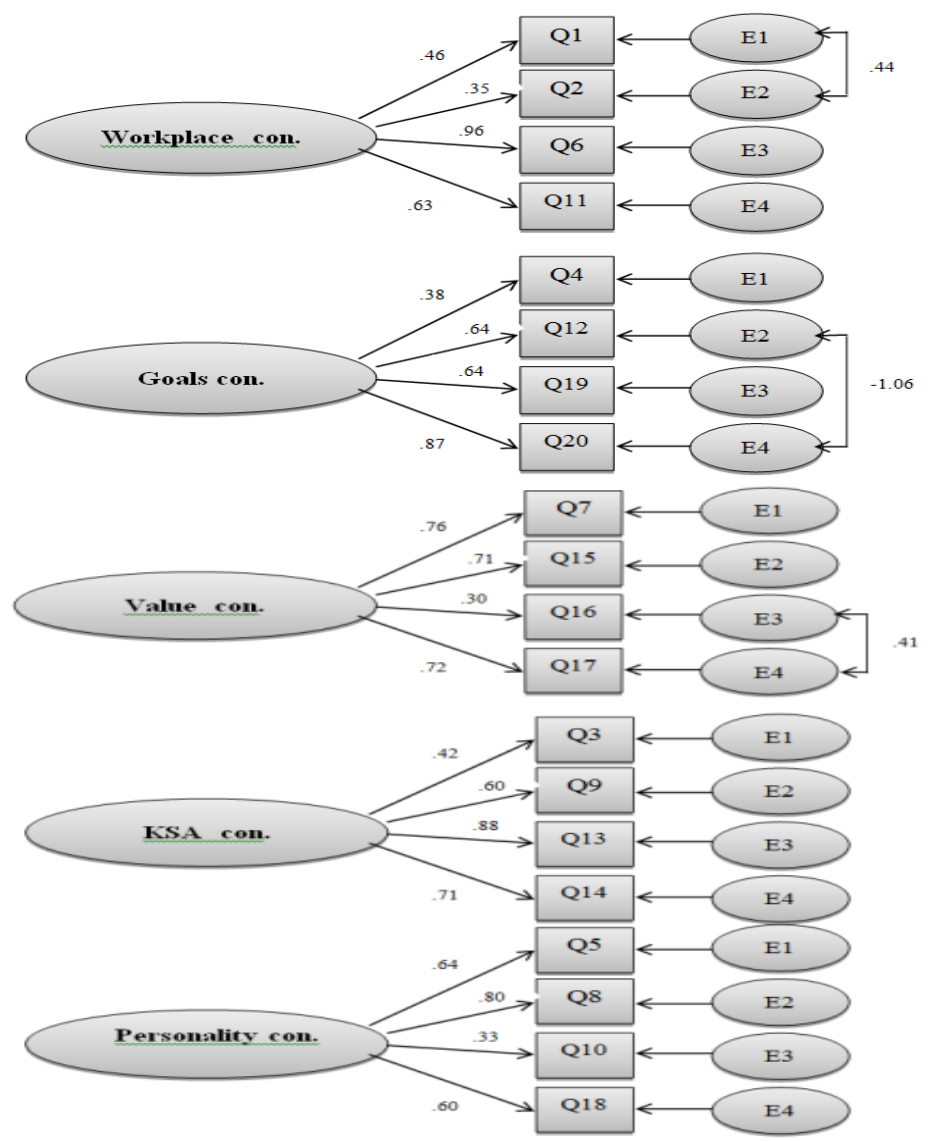

Figure 2. The Structural Equation Modeling for Person-Organization Fit Variables 
Figure 2 is shows the structural equation modeling for person-organization fit variables and Figure 3 is shows the structural equation modeling for Organizational effectiveness variables.Goodness indexes were in an acceptable range for all measurement models. These indexes showed the suitable goodness of the model and the collected data supported the model well. Factorial loads were more than 0.3 at the significance level 0.000. Having examined and confirmed the measurement models in step one, structural equation modeling was analyzed in the second step to test the hypotheses that will be mentioned separately for each hypothesis.

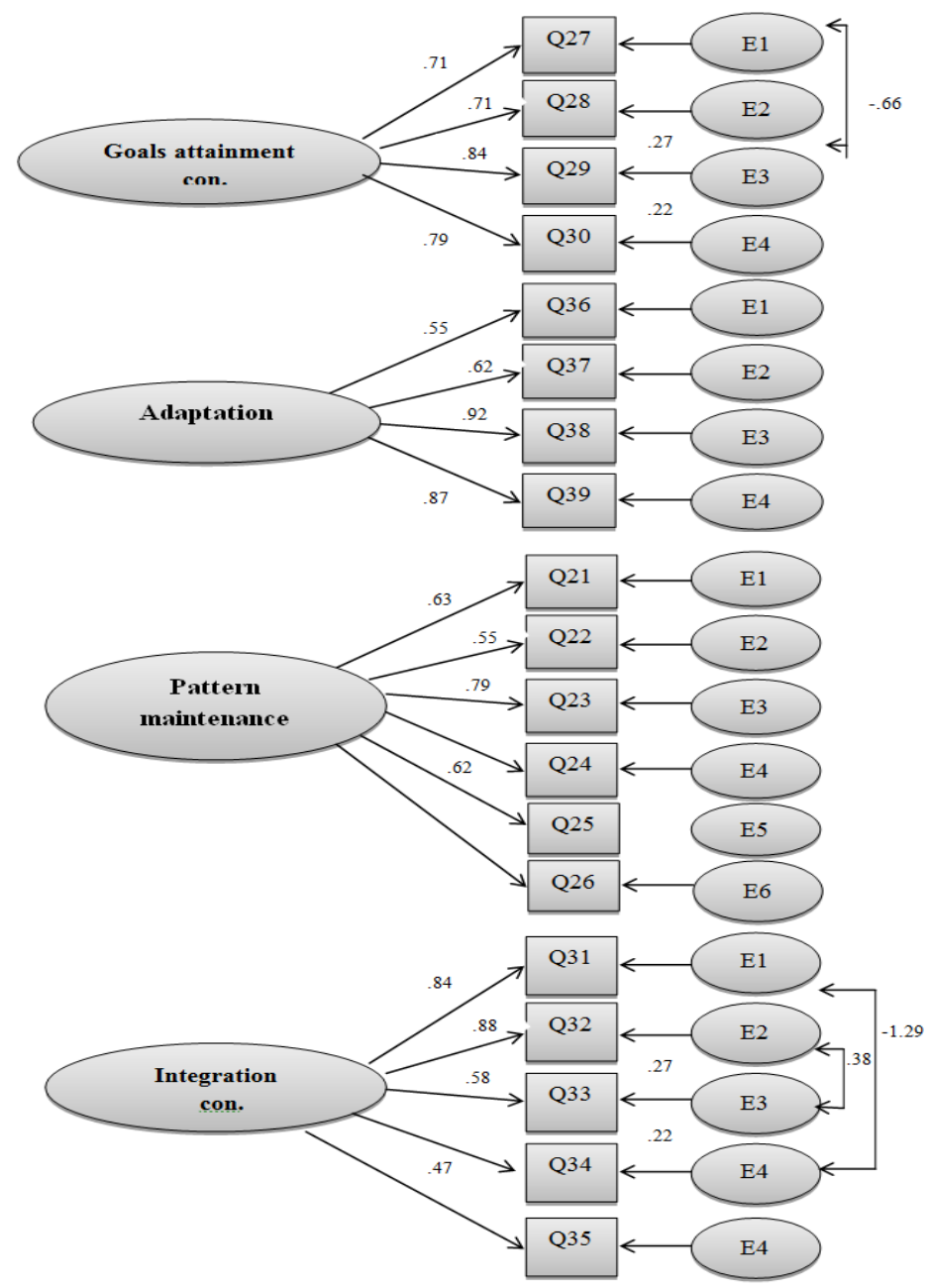

Figure 3. The Structural Equation Modeling for Organizational Effectiveness Variables

\subsection{Results of the Structural Equation Modeling Analysis}

Having explored and confirmed the measurement models, a structural equation model was used to test the hypotheses. A goodness index of the model, testing of the hypotheses, and the related model are presented in the following section.

\subsubsection{Secondary Hypothesis 1: There is a Significant Relationship between Workplace Congruence and Organizational Effectiveness among the Employees at the University of Isfahan}

The results related to the relationship between workplace congruence and organizational effectiveness is shown in Table 4.

The results of structural equation modeling show that workplace congruence with regression coefficient equal to 0.16 and significance level more than 0.05 is not effective on organizational effectiveness and secondary hypothesis 1 is rejected as shown in Figure 4. 
Table 4. Goodness Indexes of the Model

\begin{tabular}{lcccccccc}
\hline & CMIN.df & RMR & RMSEA & GFI & NFI & CFI & IFI & TLI \\
\hline Secondary model 1 & 2.33 & 0.06 & 0.07 & 0.90 & 0.90 & 0.90 & 0.90 & 0.90 \\
The accepted area & $5<\& 1>$ & $0.08>$ & $0.08>$ & $0.09<$ & $0.09<$ & $0.09<$ & $0.09<$ & $0.09<$ \\
\hline
\end{tabular}

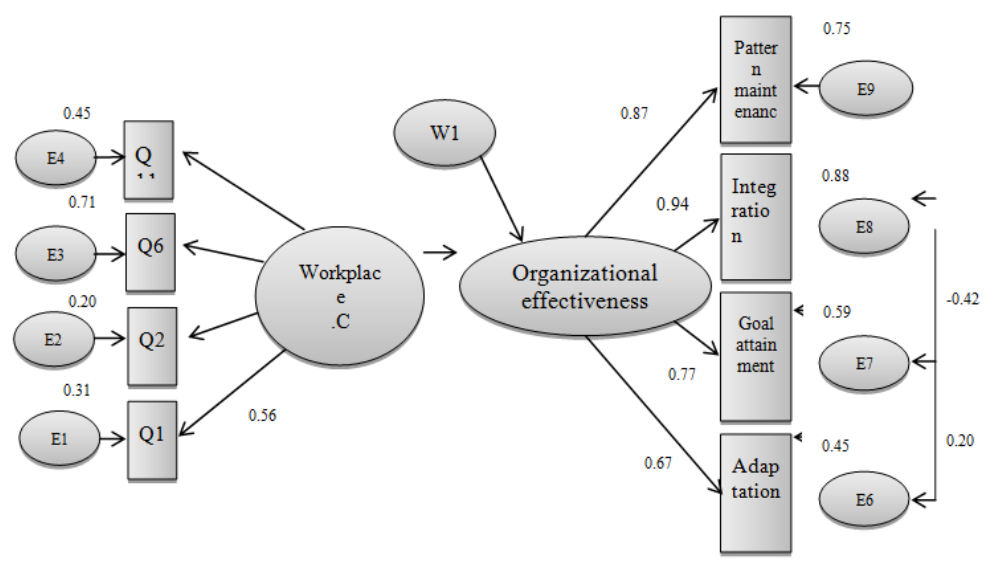

Figure 4. The Structural Equation Modeling for Secondary Hypothesis 1

3.2.2. Secondary Hypothesis 2: There is a Significant Relationship between KSA Congruence and Organizational Effectiveness among the Employees at the University of Isfahan

The results related to the relationship between goal congruence and organizational effectiveness are shown in Table 5.

Table 5. Goodness Indexes of the Model

\begin{tabular}{ccccccccc}
\hline & CMIN.df & RMR & RMSEA & GFI & NFI & CFI & IFI & TLI \\
\hline Secondary model 2 & 2.83 & 0.04 & 0.06 & 0.90 & 0.90 & 0.90 & 0.90 & 0.90 \\
The accepted area & $5<\& 1>$ & $0.08>$ & $0.08>$ & $0.09<$ & $0.09<$ & $0.09<$ & $0.09<$ & $0.09<$ \\
\hline
\end{tabular}

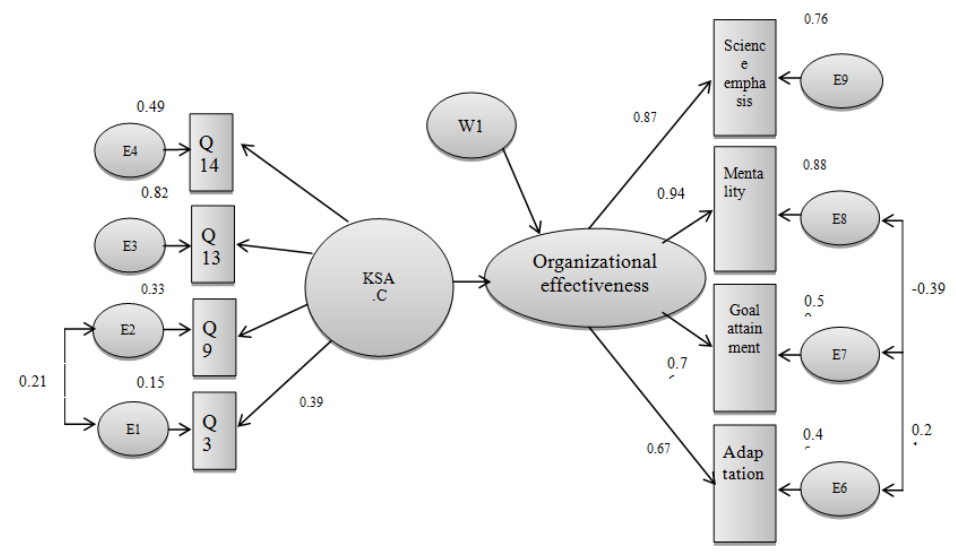

Figure 5. The Structural Equation Modeling for Secondary Hypothesis 2

The results of structural equation modeling show that KSAs congruence with regression coefficient equal to 0.05 and significance level minor than 0.05 is effective on organizational effectiveness and secondary hypothesis 2 is confirmed as shown in Figure 5. 
3.2.3. Secondary Hypothesis 3: There is a Significant Relationship between Goals Congruence and Organizational Effectiveness among the Employees at the University of Isfahan

The results related to the relationship between personality congruence and organizational effectiveness is shown in Table 6.

Table 6. Goodness Indexes of the Model

\begin{tabular}{ccccccccc}
\hline & CMIN.df & RMR & RMSEA & GFI & NFI & CFI & IFI & TLI \\
\hline Secondary model 3 & 2.04 & 0.06 & 0.07 & 0.91 & 0.90 & 0.92 & 0.92 & 0.90 \\
The accepted area & $5<\& 1>$ & $0.08>$ & $0.08>$ & $0.09<$ & $0.09<$ & $0.09<$ & $0.09<$ & $0.09<$ \\
\hline
\end{tabular}

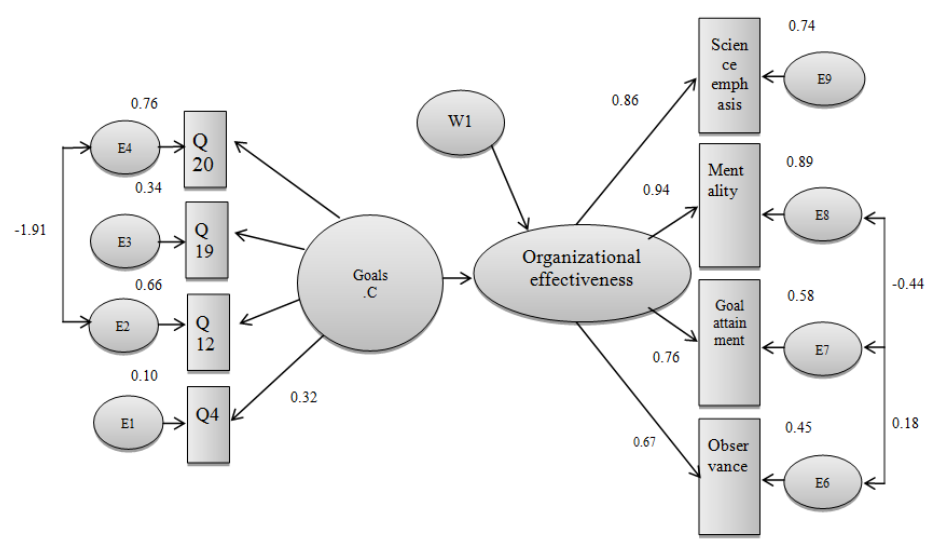

Figure 6. The Structural Equation Modeling for Secondary Hypothesis 3

The results of structural equation modeling show that goals congruence with regression coefficient equal to 0.40 and significance level minor than 0.05 is effective on organizational effectiveness and secondary hypothesis 3 is confirmed as shown in Figure 6.

\subsubsection{Secondary Hypothesis 4: There is a Significant Relationship between Personality Congruence} and Organizational Effectiveness among the Employees at the University of Isfahan

The results related to the relationship between Personality congruence and organizational effectiveness is shown in Table 7.

Table 7. Goodness Indexes of the Model

\begin{tabular}{ccccccccc}
\hline & CMIN.df & RMR & RMSEA & GFI & NFI & CFI & IFI & TLI \\
\hline Secondary model 4 & 2.17 & 0.03 & 0.05 & 0.93 & 0.91 & 0.95 & 0.95 & 0.91 \\
The accepted area & $5<\& 1>$ & $0.08>$ & $0.08>$ & $0.09<$ & $0.09<$ & $0.09<$ & $0.09<$ & $0.09<$ \\
\hline
\end{tabular}

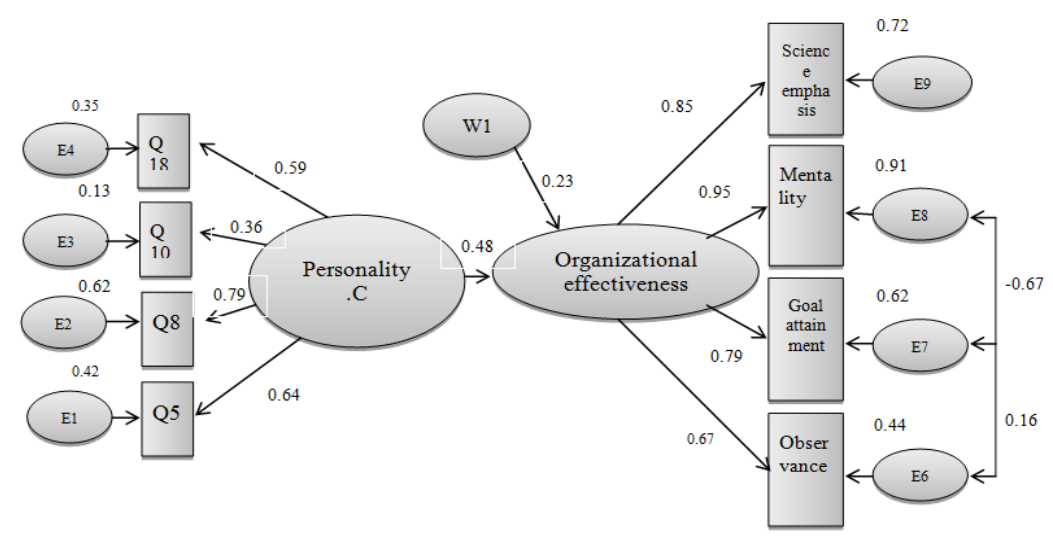

Figure 7. The Structural Equation Modeling for Secondary Hypothesis 4 
The results of structural equation modeling show that personality congruence with regression coefficient equal to 0.48 and significance level minor than 0.05 is effective on organizational effectiveness and secondary hypothesis 4 is confirmed as shown in Figure 7.

\subsubsection{Secondary Hypothesis 5: There is a Significant Relationship between Value Congruence and Organizational Effectiveness among the Employees at the University of Isfahan.}

The results related to the relationship between value congruence and organizational effectiveness is shown in Table 8.

Table 8. Goodness Indexes of the Model

\begin{tabular}{cccccccccc}
\hline & CMIN.df & RMR & RMSEA & GFI & NFI & CFI & IFI & TLI \\
\hline Secondary model 5 & 2.67 & 0.04 & 0.06 & 0.90 & 0.90 & 0.93 & 0.93 & 0.90 \\
The accepted area & $5<\& 1>$ & $0.08>$ & $0.08>$ & $0.09<$ & $0.09<$ & $0.09<$ & $0.09<$ & $0.09<$ \\
\hline
\end{tabular}

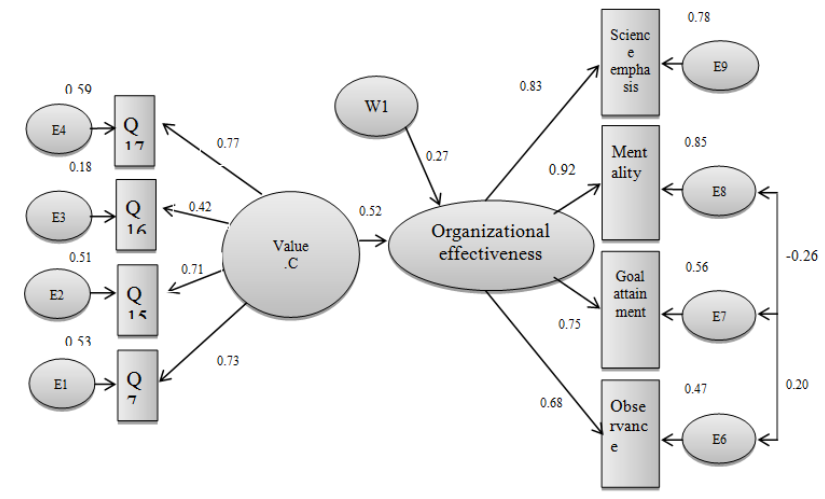

Figure 8. The Structural Equation Modeling for Secondary Hypothesis 5

The results of structural equation modeling show that value congruence with regression coefficient equal to 0.52 and significance level minor than 0.05 is effective on organizational effectiveness and secondary hypothesis 5 is confirmed as shown in Figure 8.

\subsubsection{Main Hypothesis: There is a Significant Relationship between Person-Organization Fit and} Organizational Effectiveness among the Employees at the University of Isfahan.

The results related to the relationship between person-organization fit and organizational effectiveness are shown in Table 9.

Table 9. Goodness Indexes of the Model

\begin{tabular}{ccccccccc}
\hline & CMIN.df & RMR & RMSEA & GFI & NFI & CFI & IFI & TLI \\
\hline Main model & 2.45 & 0.04 & 0.05 & 0.91 & 0.90 & 0.93 & 0.93 & 0.90 \\
The accepted area & $5<\& 1>$ & $0.08>$ & $0.08>$ & $0.09<$ & $0.09<$ & $0.09<$ & $0.09<$ & $0.09<$ \\
\hline
\end{tabular}

The results of structural equation modeling show that person organization fit with regression coefficient equal to 0.49 and significance level minor than 0.05 is effective on organizational effectiveness and main hypothesis is confirmed as shown in Figure 9.

The results from the Amos software in the section related to standard model estimation revealed that the path analysis model is a suitable model. That is: a) the value of normal chi-square was between one and five; b) the RMSEA value was less than 0.08 , and suitable; c) the values of the CFI and the four indexes of NFI, CFI, TLI, and IFI were close to each other and greater than 90 percent; and, d) the RMR value was close to zero. Also, values of goodness indexes for the models were acceptable and showed suitable goodness of fit by the data. The collected data supported the models well. The hypotheses, along with regression coefficients and values of partial indexes related to each hypothesis, are shown separately in the Table 10. 


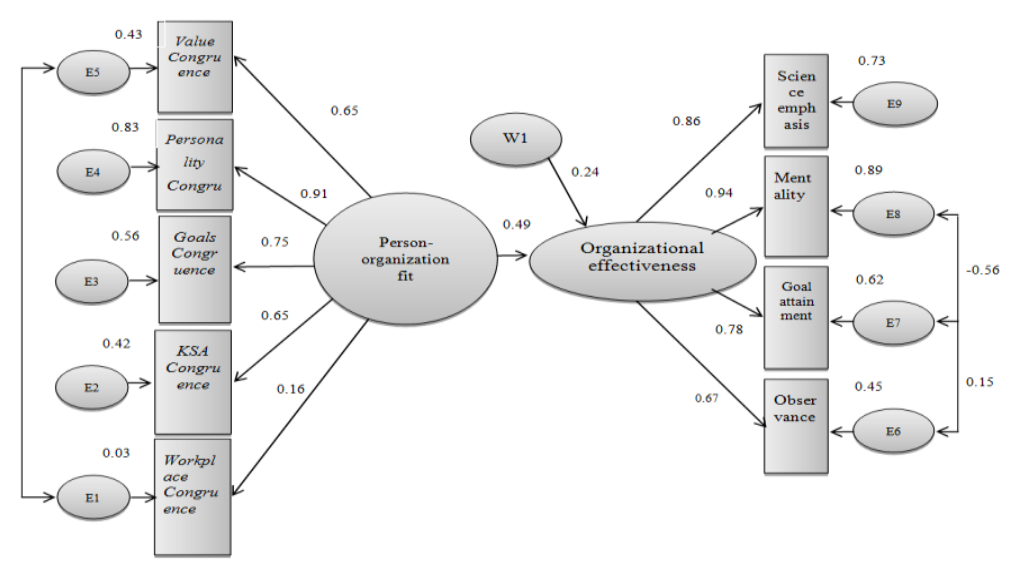

Figure 9. The Structural Equation Modeling for Main Hypothesis

Table 10 is shows testing the hypotheses.

Table 10. Testing the Hypotheses

\begin{tabular}{|c|c|c|c|c|c|c|}
\hline Test results & $\begin{array}{l}\text { Correlation } \\
\text { coefficient }\end{array}$ & $\begin{array}{c}\text { Significant } \\
\text { number }\end{array}$ & $\begin{array}{l}\text { Sample } \\
\text { volume }\end{array}$ & \multicolumn{3}{|c|}{ Hypothesis } \\
\hline Confirm & 0.49 & 0.031 & 2.61 & $\begin{array}{l}\text { Organizational } \\
\text { effectiveness }\end{array}$ & $\leftarrow$ & Person-individual fit \\
\hline Rejection & 0.16 & 0.13 & 1.48 & $\begin{array}{l}\text { Organizational } \\
\text { effectiveness }\end{array}$ & $\leftarrow$ & workplace congruence \\
\hline Rejection & 0.05 & 0.62 & 0.48 & $\begin{array}{l}\text { Organizational } \\
\text { effectiveness }\end{array}$ & $\leftarrow$ & KSA congruence \\
\hline Confirm & 0.40 & 0.002 & 3.17 & $\begin{array}{l}\text { Organizational } \\
\text { effectiveness }\end{array}$ & $\leftarrow$ & goal congruence \\
\hline Confirm & 0.48 & 0.000 & 3.92 & $\begin{array}{l}\text { Organizational } \\
\text { effectiveness }\end{array}$ & $\leftarrow$ & personality congruence \\
\hline Confirm & 0.52 & 0.000 & 4.61 & $\begin{array}{l}\text { Organizational } \\
\text { effectiveness }\end{array}$ & $\leftarrow$ & value congruence \\
\hline
\end{tabular}

\section{CONCLUSION}

As mentioned earlier, person-organization fit is associated with organizational effectiveness. Since person-organization fit refers to the fit of an individual's characteristics and those of the organization in which he.she works, exploring the relationship between dimensions and organizational citizenship behavior can be important. Given the importance of person-organization fit and organizational effectiveness in an academic and research environment such as a university, the statistical population included employees (experts and managers) of the University of Isfahan. From the population of 150 employees, 120 were selected for the research sample. This was a descriptive study in terms of data collection and analysis procedures. Similarly, it was cross-sectional in terms of time.

Studies which have been conducted about the person organization fit theory are to some extent weak in adding and examining the outcome variables. Likewise, standards of measuring person organization fit have only been used in similar fields of studies so that little attention has been paid to studying the universities and educational institutions. Hence, this study selected a field that has been less investigated and on the other hand, the importance of this topic for such environment (university) is special in terms of the role that this environment plays to train human capitals.

Considering the role of person organization fit and its four standards in organizational effectiveness, it is suggested that universities (organizations) prepare a perfect planning for the use of potential of person organization fit theory given the proposed standards and relations in this study. It is suggested to future researchers to explore and determine the effective factors on organizational effectiveness in universities considering the effects of cultural variables on these factors by conducting similar studies and investigate how people in organizations can achieve the required information to proportion person organization fit standards to their organization, because how these standards affect organizational effectiveness was investigated in the present research but it was not determined those who want to obtain a higher level of fit need which kind of information and how they can achieve that information. 


\section{REFERENCES}

[1] A. Agus, et al., "An exploratory study of service quality in the Malaysian public service sector," International Journal of Quality \& Reliability Management, vol/issue: 24(2), pp. 177 - 190, 2007.

[2] S. A. Carless, "Person-job Fit versus person-organization Fit as predictors of organizational attraction and job acceptance intentions: a longitudinal study," Journal of Occupational and Organizational Psychology, vol. 78, pp. 411-429, 2005.

[3] Kristof A. L., "Person-organization fit: An integrative review of its conceptualizations, measurements, and implications," Personnel Psychology, vol. 49, 1996.

[4] B. Vilela, et al., "Person-organization fit, CB and performance; an empirical investigation in the Spanish sales context," Industrial Marketing Management, vol. 37, pp. 1005-1019, 2008.

[5] W. J. Aprill and T. C. Huang, "Relationship between SHRM and firm Performance," International Journal of Manpower, vol/issue: 40(3), pp. 88-171, 2005.

[6] M. Armstrong, "Strategies for human resource management: A total business approach," Coopers \& Lybrand, 1993.

[7] H. Teimouri, et al., "Examining the Relationship between Person-Organization Fit and Organizational Citizenship Behavior: The Case of an Educational Institution," Annals of Management Science, vol/issue: 4(1), pp. 23-44, 2015.

[8] W. K. Hoy and C. G. Mishkel, "Educational Administration: Theory, Research and Practice," $7^{\text {th }}$ edition, New York, McGraw-Hill, 2005.

[9] R. N. Beigi, "Organization and management," Tehran, Termeh Publications, 2010. [in Persian].

[10] G. H. Rahimi, et al., "Investigating the relationship between managers' multiple intelligence and organizational effectiveness in the Gas Company in East Azerbaijan province," Journal of Management, vol. 22, pp. 21-34, 2013. [in Persian].

[11] L. Ba, "Knowledge Management and Organizational Culture, A Social Action Perspective," Doctoral Dissertation. George Washington University, Retrived from Proquest Dissertation Database, (UMINO.3126188), 2004.

[12] J. Billsberry, "Attracting for values: an emprical study of ASA, attraction proposition," Journal of Managerial Psychology, vol/issue: 22(2), 2007.

[13] M. Abzari, et al., "Exploring the effect of person organization fit and organizational culture on organizational behavior of faculty members," Human Sciences MODARES-Iranian Journal of M anagement Studies, vol. 2, pp. 510, 2010. [in Persian].

[14] A. Gholipour, et al., "Explaining person organization fit as an effective factor on work alienation and work engagement," Strategic Management Thought, vol. 1, pp. 211, 212, \& 225, 2010. [in Persian].

[15] J. B. Hoffman and J. D. Woehr, "A quantitative review of the relationship between person-organization Fit and behavioral outcomes," Journal of Vocational Behavior, vol. 68, pp. 389-399, 2006.

[16] T. Sekoguchi, "How do organizations promote person- environment fit? The Japanese case and future research agende," presented at the Asia Academy of Management, 2003.

[17] C. Argyris, "The individual and organization: Some problems ofmutual adjustment," Administrative Science quarterly, vol. 2, pp. 8-14, 1957.

[18] D. Coldwell, et al., "The effect of personorganization ethical fit on employee attraction and retention: Towards a testable explanatory model," Journal of Business Ethics, vol/issue: 78(4), pp. 611-622, 2008.

[19] G. Abbott, et al., "Linking values and organization commitment: Acorrelational and experimental investigation in two organizations," Journal of Occupational Psychology, vol. 78, pp. 4, 2005

[20] L. Q. Yang, et al., "Person-environment fit or person plus environment: A meta-analysis of studies using polynomial regression analysis," Human Resource Management Review, vol. 18, pp. 311-321, 2008.

[21] T. Sekiguchi, "A contingency perspective of the importance of PJ fit and PO fit in employee selection," Journal of Managerial Psychology, vol/issue: 22(2), pp. 118-131, 2007.

[22] J. A. Chatman, "Matching people and organization selection and socialization in public accounting firms," Adminstrative science Quartery, vol/issue: 36(3), pp. 456-84, 1991.

[23] R. D. Bretz and T. A. Judge, "Person- organization fit and the theory of work adjustment: Implications for satisfaction, tenure, and career success," Journal of Vocational Behavior, vol. 44, pp. 32-54, 1994

[24] O'Reilly C. A., et al., "People and organizational culture: A profile comparison approach to assessing personorganization fit," Academy of Management Journal, vol. 34, 1991.

[25] W. W. James, "An integrative analysis of person-organization fit: effects on individual attitudes and behaviour," Ph.D thesis. UmI. Company, USA, 1997.

[26] V. R. Tom, "The Role of Personality and Organizational Images in the Recruting Process," Organizational Behavior and Human Performance, vol. 6, 1971.

[27] B. Schneider, et al., "The ASA framework: An update,” Personnel Psychology, vol. 48, pp. 747-773, 1995. 